\title{
Experimental Investigation of Thermosyphon for Different Parameters
}

\author{
Ajay D. Pingale ${ }^{1}$, Chetan M. Patil ${ }^{2}$, Parag B. Marathe ${ }^{3}$ \\ ${ }^{1,2,3}$ (Department of Mechanical Engineering, Dr. D Y Patil School of Engineering, Charoli, Pune)
}

\begin{abstract}
Heat transfer characteristics of circular Two phase closed thermosyphon (TPCT) charged with different fluids (Propylene Glycol and Ethylene Glycol) of $1000 \mathrm{~mm}$ length and $19 \mathrm{~mm}$ outside diameter were determined for different fill volume ratio $(40 \%$ and $60 \%)$, inclination angle $\left(0^{\circ}\right.$ to $50^{\circ}$ from vertical) and heat input supplied $\left(60^{\circ} \mathrm{C}\right.$ to $\left.80^{\circ} \mathrm{C}\right)$. An experimental study was performed on TPCT charged with EG and PG with different fill volume ratio and results obtained were compared for all inclination and heat inputs setup developed. The efficiencies of TPCT found to be deteriorate with respect to increase in inclination angle for both the fluids. Optimum inclination angle for PG-TPCT is $20^{\circ}$ to $30^{\circ}$ and that for EG-TPCT is $20^{\circ}$ to $30^{\circ}$ for both fill volume ratio. With increase in a heat input the efficiencies were begin to increase but less affected with fill volume ratio. The average efficiency of EG-TPCT is found to be higher.
\end{abstract}

Keywords: Two phase closed thermosiphon (TPCT), EG, PG.

\section{Introduction}

The heat pipe is an effective heat transfer device. It is a device having a very high thermal conductance. The idea of heat pipe was first introduced by the Perkins family in the nineteen century for which they receive the UK Patent No. $7059^{[1]}$ for using small quantity of water in Perkins tube and operating on a two phase cycle. Later on this concept was more developed by Gaugler in 1942. In the today's world, the scientific community is striving for effective utilization of energy. The heat transfer characteristics of TPCT have been investigated by many researchers for various types of fluids like water, alcohols, refrigerants etc. but most of the investigations have been limited to either low or high heat inputs.

Ajit M. Kate et. al. ${ }^{[4]}$ studied the effect of cross sectional geometries, working fluid fill charge, heat input and inclination angle on the performance of wickless heat pipe has been investigated experimentally. The experimental results indicate that the temperature distribution along wall surface of elliptical cross section was higher than circular section geometry wickless heat pipe. The liquid film in the evaporator was dried out when fill charge is less and heat inputs are higher. The heat inputs had very significant effect on wickless heat pipe having less working fluid fill charge. The elliptical cross section pipe shows better performance than circular cross section wickless heat pipes at higher heat inputs. Highest heat transfer coefficient was observed between inclinations of around $10^{\circ}$ to $20^{\circ}$.

M. Karthikeyan et al. ${ }^{[5]}$ studied the thermal performance of an inclined two phase closed thermosyphon with different working fluid had been investigated experimentally. Based on the results obtained they draws the following conclusions, the thermal resistance is indirectly proportional to the heat input which means with the increase of heat input, the thermal resistance of thermosyphon decreases. The heat transfer coefficient increases with the increase in heat flux. The evaporator (boiling) heat transfer coefficient is slightly higher than the condensation heat transfer coefficient. Performance of two phase closed thermosyphon with aqueous solution of $\mathrm{n}$-butanol has the maximum thermal performance than that of two phase closed thermosyphon with de-ionized water.

Y. Gandal et. al ${ }^{[6]}$ conducted experiment to study the heat transfer characteristic of two phase closed thermosyphon (TPCT) using Propylene Glycol (PG) is analyzed experimentally and compared with Deionized (DI) water for different inclinations and heat input. The experimental results indicate that the Propylene Glycol thermosyphon works better at higher heat inputs and the optimum inclination angle for PG thermosyphon is between $20^{\circ}-30^{\circ}$ and that for DI water is $10^{\circ}$ to $20^{\circ}$. The TPCT is an efficient heat transfer device due to their high heat transfer capabilities with no exterior power requirement. It transfers a large amount of heat with very small temperature difference. It is vertically oriented with liquid pool at bottom. Heat is given to evaporator section and vapour forms rises up to the condenser section where it condense heat to the surrounding and return to the evaporator section along with the tube wall due to gravitational force. The main benefit of TPCT is that it requires no mechanical pumping and which makes it inexpensive and reliable.

E. Hahne et. al.$^{[7]}$ an experimental investigation was performed in order to observe the effect of the inclination angle on the transport behavior of a closed two-phase thermosyphon. An effective thermal conductivity of the thermosyphon is found to be strongly depending on inclination and heat flow rate. Separate consideration of the transport regimes in the various zones showed their individual influence upon the overall behavior. The 
condensation in the cooling zone exhibits the largest transport resistance. The heat transfer with boiling in the heating zone shows large local differences and depends strongly on inclination.

C. Wang et. al. ${ }^{[8]}$ performed an experimental study on heat transfer performance of a gravity-assisted heat pipe is described. 'Dowtherm A' has been used as working fluid. The effect of fill volume ratio, inclination angle, thermal resistance and heating length ratio on the rate of heat flow were investigated. The maximum rate of heat flow increases along with the decrease of fill ratio and heat length ratio. The range of optimum inclination is within $30^{\circ}$ to $60^{\circ}$.

\section{Experimental Work}

Based on the literature review the following factors were finalized for the present experimental work.

Table 1: Parameters Selection for Thermosyphon

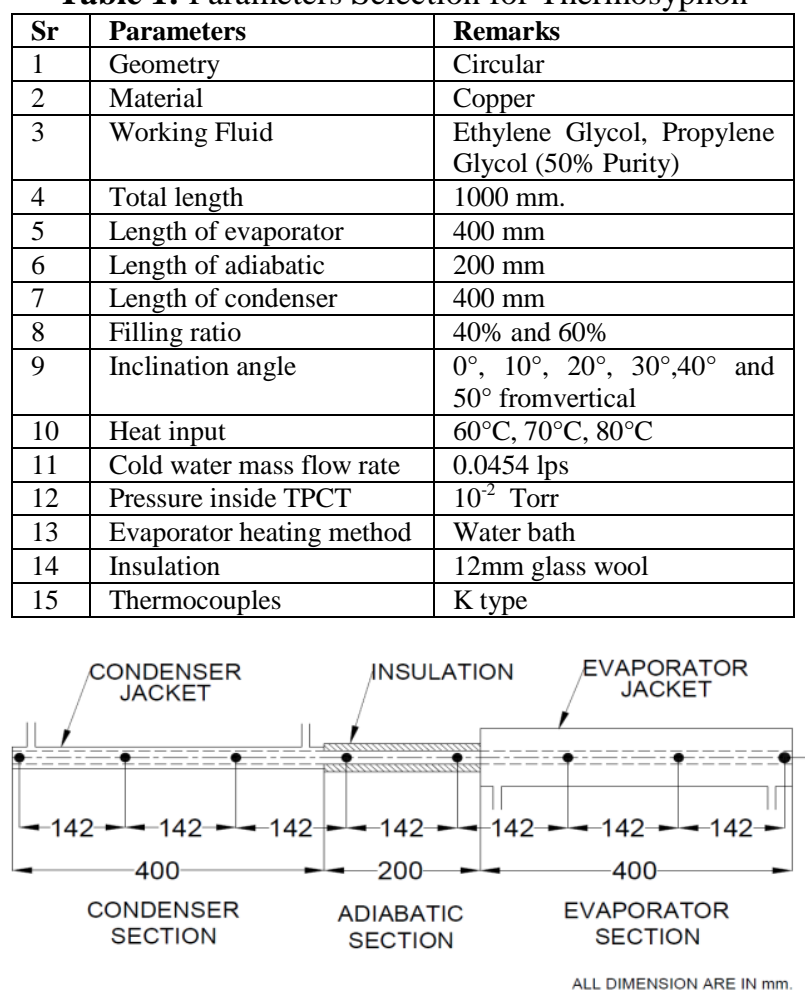

Figure 1: Location of Thermocouples on TPCT

For conducting the experimentation four copper TPCT's of same dimensions $(\mathrm{L}=1000 \mathrm{~mm}, \mathrm{ID}=17$ $\mathrm{mm}$ and $\mathrm{OD}=19 \mathrm{~mm}$ ) were designed. TPCT's are charged with fill volume (the ratio of liquid volume filled to the total volume of evaporator section) of $40 \%$ and $60 \%$ with respective working fluids filled under the pressure of $10^{-2}$ Torr. The set up consists of hot water tank, evaporator jacket and condenser jacket along with measuring instruments. The hot water tank is used to heat up the water and this hot water is circulated in evaporator jacket with electric motor pump of $0.25 \mathrm{hp}$. The tank is incorporated with $1000 \mathrm{~W}$ heater to heat the cold water in the hot water tank. Evaporator jacket is a rectangular tank in which TPCT is placed. The hot water from hot water tank is allowed to enter in the evaporator jacket, which heats up the evaporative section of TPCT. Condenser jacket is made up of PVC pipe of $31.25 \mathrm{~mm}$ ID; it acts as a cooling water jacket and is used to remove the heat from the condenser section.

The TPCT has the ability to transfer large amount of heat. As a result of which, a sudden rise in the wall temperature would damage the TPCT when the heat is not released correctly at the condenser end. Therefore, cooling water is dispersed first through the water jacket before supplying the heat to evaporator section. Flow rate of water is kept constant at $0.033 \mathrm{~kg} / \mathrm{sec}$ in both the sections and it is measured by the amount of the water flows over an interval of time. Digital temperature indicator of 12 channels is used to display the temperature. Three thermocouples are installed on evaporator section $(\mathrm{Le}=400 \mathrm{~mm})$; three are on condenser $(\mathrm{Lc}=400 \mathrm{~mm})$ and two on adiabatic section $(\mathrm{La}=200 \mathrm{~mm})$. In addition to that, two thermocouples are placed at hot water tank and condenser jacket inlet and outlet. The surface temperature distribution of the TPCT is measured with eight copper constantan (K type) thermocouples with an accuracy of $\pm 1{ }^{\circ} \mathrm{C}$ as shown in Fig.4.2.2. Three thermocouples are installed on evaporator section $(\mathrm{Le}=400 \mathrm{~mm})$; three are on condenser $(\mathrm{Lc}=400 \mathrm{~mm})$ and two on adiabatic section $(\mathrm{La}=200 \mathrm{~mm})$. In addition to that, two thermocouples are placed at hot water tank and condenser jacket inlet and outlet. 
A PID controller is used to cut off the heater by sensing evaporator jacket temperature. This thermocouple makes the assurance of desired temperature achievement in evaporator jacket. The hot water is continuously circulated from hot water tank to evaporator jacket so as to achieve uniform temperature in evaporator jacket. Glass wool insulation of $12 \mathrm{~mm}$ thickness is provided to adiabatic section, evaporator jacket, hot water tank and piping systems to avoid the heat loss to the surrounding. An energy meter is provided to measure energy consumption while conducting the experimentation. An angle holder slot is made available for giving tilt to TPCT from $0^{\circ}$ to $60^{\circ}$ inclination with a step size of $10^{\circ}$ from vertical.

The experimental procedure consists of four identical TPCT of same dimensions as mentioned above. One is charged with ethylene glycol and other with propylene glycol with $50 \%$ purity with $40 \%$ and $60 \%$ as a fill volume ratio. Initially heater is on and water is allowed to get heated in hot water tank. This hot water is continuously circulated in the evaporator jacket with the help of motor which ensures uniform temperature achievement in evaporator jacket. PID controller is provided to cut the heater, when the desired temperature is reached in evaporator jacket.

\section{Observation from Experimental Work}

The experimental study was performed to compare the thermal performance of two phase closed thermosyphon charged with propylene glycol and EG as a working fluid. The TPCT is tested for different fill volume ratio, inclination angle and heat input supplied from which the following points were studied in detail. Evaporator heat transfer coefficient (he):

The heat absorption capacity of evaporator section of TPCT is determined by heat transfer coefficient (he) which is given by equation (1),

he $=\mathrm{Qe} /\left(\pi^{*} \mathrm{di}^{*} \mathrm{Le} *(\Delta \mathrm{Te}-\Delta \mathrm{Ta})\right)$

Where, Qe is the rate of heat absorbed by the evaporator section of TPCT from the hot water of the evaporator jacket and is obtained from the equation (2) as mentioned below,

$\mathrm{Qe}=\mathrm{me}^{*} \mathrm{Cp} *($ Teti-Teto $)$

Where,

me $=0.033 \mathrm{~kg} / \mathrm{s} ; \mathrm{C}_{\mathrm{p}}=4187 \mathrm{j} / \mathrm{kg}-{ }^{\circ} \mathrm{C}$, Teto $=63.4^{\circ} \mathrm{C}$ and $\mathrm{Teti}=58.2^{\circ} \mathrm{C}$,

$($ Teti-Teto $)=63.4-58.2 \approx 6^{\circ} \mathrm{C}$

$\mathrm{Qe}=0.033 * 4187 * 6=829.03 \mathrm{~W}$

Since, $\Delta \mathrm{Te}=(\mathrm{Te} 1+\mathrm{Te} 2+\mathrm{Te} 3) / 3$ and $\mathrm{Ta}=(\mathrm{Ta} 1+\mathrm{Ta} 2) / 2$

$\Delta \mathrm{Te}=(53.9+51.5+52.7) / 3=52.7^{0} \mathrm{C}$

Similarly, $\Delta \mathrm{Ta}=(48.8+47.9) / 2=48.35{ }^{0} \mathrm{C}$

he $=829.03 /(\pi * 0.017 * 0.4 *(52.70-48.35))$

$$
=7984 \mathrm{~W} / \mathrm{m}^{2}-{ }^{0} \mathrm{C}
$$

Condenser heat transfer rate $(Q c)$

The amount of heat transferred by condenser section to the surrounding cold water in condenser jacket is calculated by considering the mass flow rate and specific heat and inlet and outlet temperature difference of water, as given in equation (3)

$\mathrm{Qc}=\mathrm{mc} * \mathrm{Cp} *$ (Tco-Tci)

Where,

$\mathrm{mc}=0.033 \mathrm{~kg} / \mathrm{s} ; \mathrm{C}_{\mathrm{p}}=4187 \mathrm{j} / \mathrm{kg}-{ }^{\circ} \mathrm{C}, \mathrm{Tco}=35.4^{\circ} \mathrm{C}$ and $\mathrm{Tci}=29^{\circ} \mathrm{C}$

$\mathrm{Qc}=0.033 * 4187 *(35.4-29)=884.29 \mathrm{~W}$

Condenser heat transfer coefficient (hc)

The heat transfer capacity of condenser section for TPCT is determined by heat transfer coefficient (hc) which is evaluated by using equation (4)

$\mathrm{hc}=\mathrm{Qc} /\left(\pi * \mathrm{di}^{*} \mathrm{Lc} *(\Delta \mathrm{Ta}-\Delta \mathrm{Tc})\right.$

Where, $\mathrm{Qc}=884.29 \mathrm{~W}$,

$\Delta \mathrm{Ta}=48.35{ }^{\circ} \mathrm{C}$ and $\Delta \mathrm{Tc}=37.37{ }^{\circ} \mathrm{C}$

$\mathrm{hc}=884.29 /\left(\pi^{*} 0.017-0.4 *(48.35-37.37)\right)=3373 \mathrm{~W} / \mathrm{m}^{2}{ }^{0} \mathrm{C}$

Development of thermal resistance $\left(R_{t h}\right)$

The thermal resistance of the TPCT gives the amount of resistance observed by the heat flow from evaporator to condenser section. It is the average temperature difference between the evaporator and condenser to the amount of heat absorbed by TPCT which is calculated by expression (5),

$\mathrm{Rth}=(\Delta \mathrm{Te}-\Delta \mathrm{Tc}) / \mathrm{Qe}$

Where, $\Delta \mathrm{Te}=52.7^{\circ} \mathrm{C}, \Delta \mathrm{Tc}=37.37^{\circ} \mathrm{C}$ and

$\mathrm{Qe}=829.03 \mathrm{~W}$

$\mathrm{Rth}=(52.7-37.37) / 829.03=0.00185^{\circ} \mathrm{C} / \mathrm{W}$ 


\section{Efficiency of thermosyphon}

The efficiency of TPCT is calculated as the ratio of amount of heat rejected (hc) by the condenser to the amount of heat absorbed (he) by the evaporator section of the TPCT.

$\eta=\mathrm{hc} / \mathrm{he}$

Where, hc $=3373 \mathrm{~W} / \mathrm{m}^{2}{ }_{-}{ }^{0} \mathrm{C}$ and he $=7984 \mathrm{~W} / \mathrm{m}^{2}{ }_{-}{ }^{0} \mathrm{C}$

$\eta=3373 / 7984=42.25 \%$

During experimentation it is required to achieve steady state for accurate reading. To achieve steady state we took 10 readings for each heat input, fill volume ratio and inclination.

For the calculation purpose we considered all above parameters like Evaporator heat transfer coefficient, condenser heat transfer rate, condenser heat transfer coefficient, thermal resistance and efficiency.

\section{Results And Discussion}

Temperature reading on thermosyphon surface is required to calculate thermal properties. We took readings of temperature from experimentation for different parameters. The variation in temperature shows the behavior of TPCT. From those temperature readings we calculated thermal properties like thermal efficiency, thermal resistance and heat transfer coefficient. Following readings and graphs shows temperature distribution, thermal efficiency and thermal resistance of TPCT.

\section{Temperature distribution along length of TPCT}

Following table shows distribution of temperature along a length of Thermosyphon. In which $\mathrm{T}_{\mathrm{e} 1}, \mathrm{~T}_{\mathrm{e} 2}$, $\mathrm{T}_{\mathrm{e} 3}$ are the temperatures at evaporator section; $\mathrm{T}_{\mathrm{A} 1}, \mathrm{~T}_{\mathrm{A} 2}$ are the temperatures at adiabatic section and $\mathrm{T}_{\mathrm{c} 1}, \mathrm{~T}_{\mathrm{c} 2}, \mathrm{~T}_{\mathrm{c} 3}$ are the temperatures at condenser section. From these readings we plot a graph of Temperature $\left({ }^{\circ} \mathrm{C}\right)$ Vs Length of TPCT $(\mathrm{mm})$ for different inclination angle.

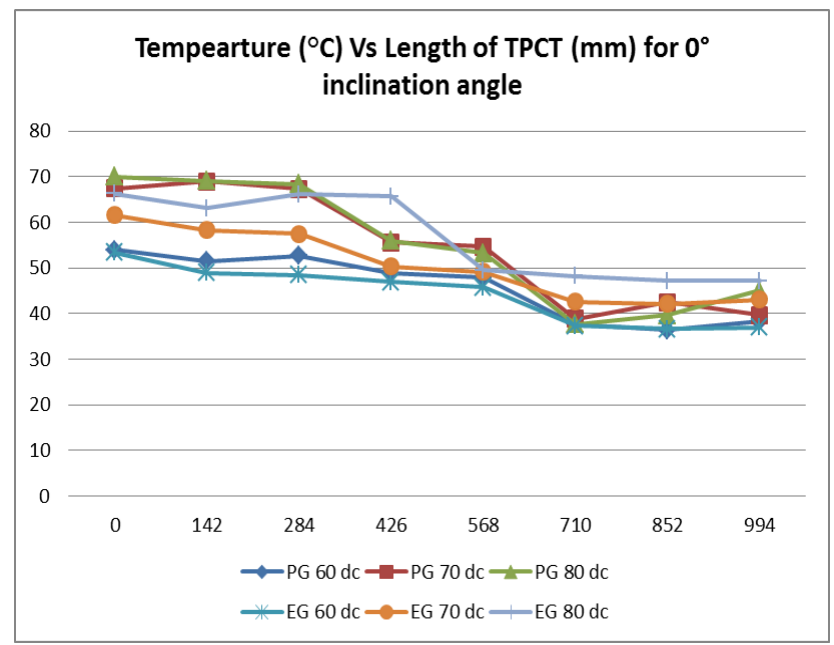

Figure 2: Plot of Temperature $\left({ }^{\circ} \mathrm{C}\right) \mathrm{Vs}$ Length of TPCT $(\mathrm{mm})$ for $0^{\circ}$ inclination angle

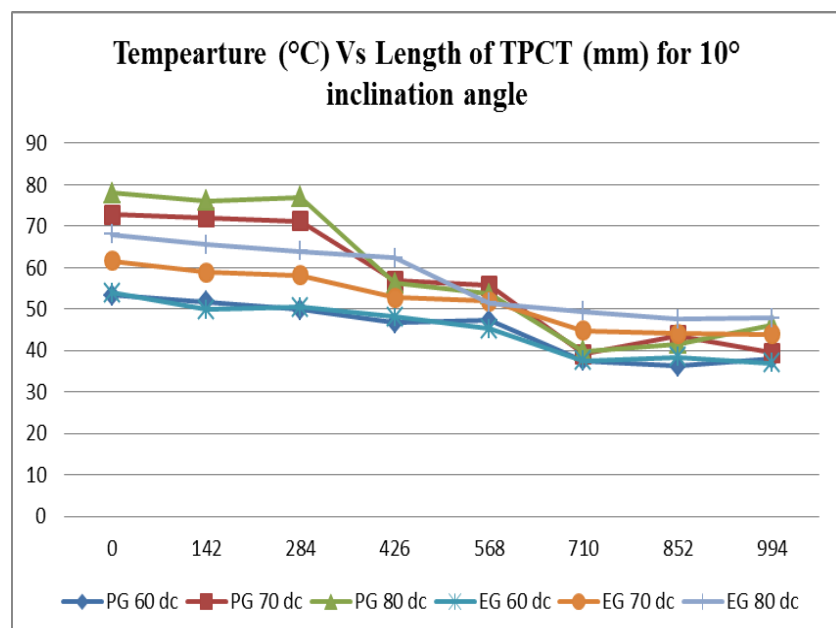

Figure 3: Plot of Temperature $\left({ }^{\circ} \mathrm{C}\right)$ Vs Length of TPCT $(\mathrm{mm})$ for $10^{\circ}$ inclination angle 


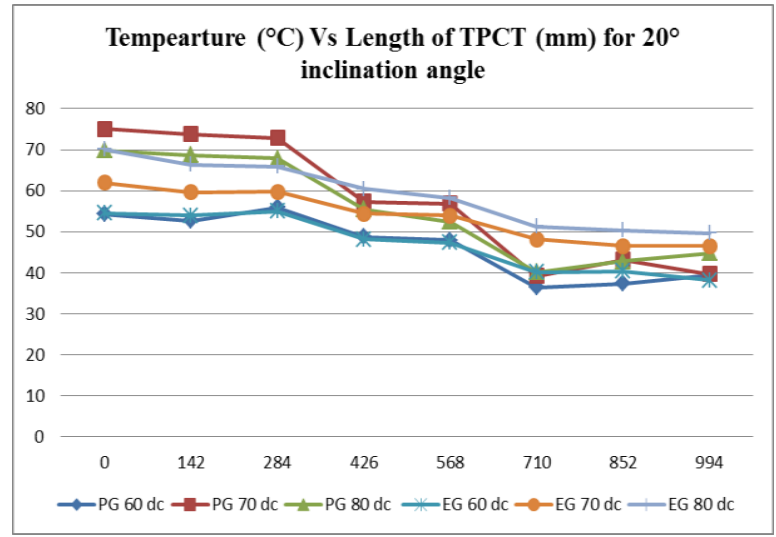

Figure 4: Plot of Temperature $\left({ }^{\circ} \mathrm{C}\right)$ Vs Length of TPCT $(\mathrm{mm})$ for $20^{\circ}$ inclination angle

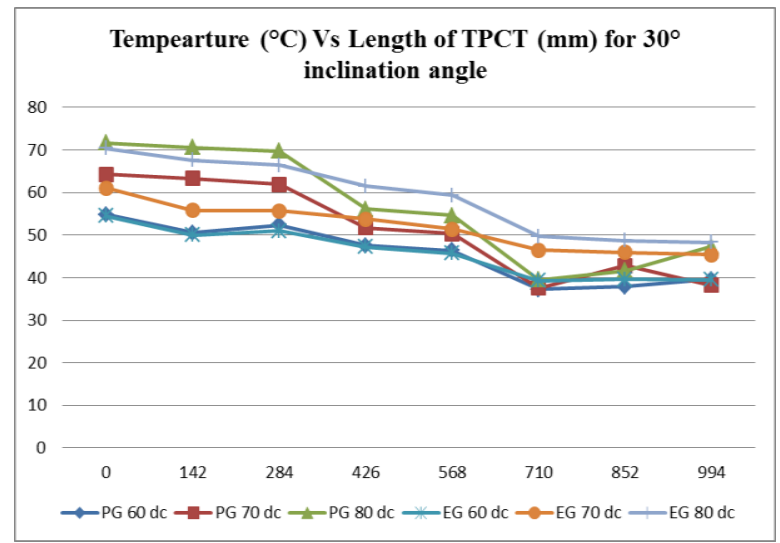

Figure 5: Plot of Temperature $\left({ }^{\circ} \mathrm{C}\right)$ Vs Length of TPCT $(\mathrm{mm})$ for $30^{\circ}$ inclination angle

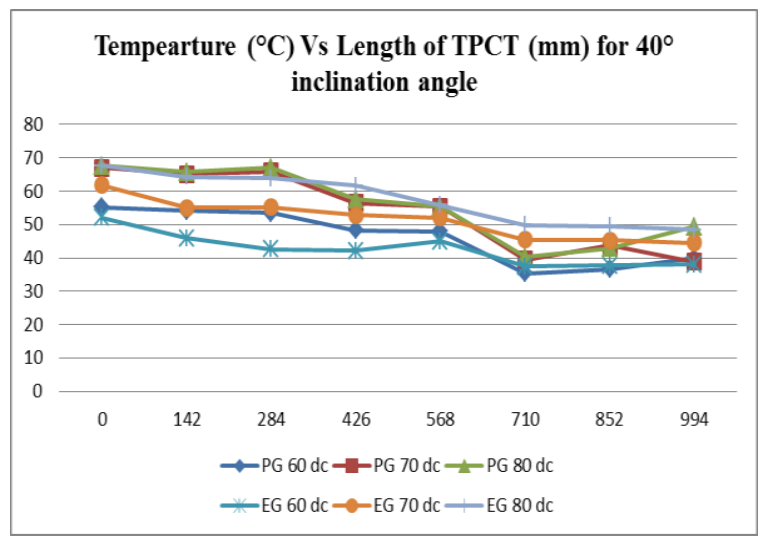

Figure 6: Plot of Temperature $\left({ }^{\circ} \mathrm{C}\right) \mathrm{V}$ s Length of TPCT $(\mathrm{mm})$ for $40^{\circ}$ inclination angle

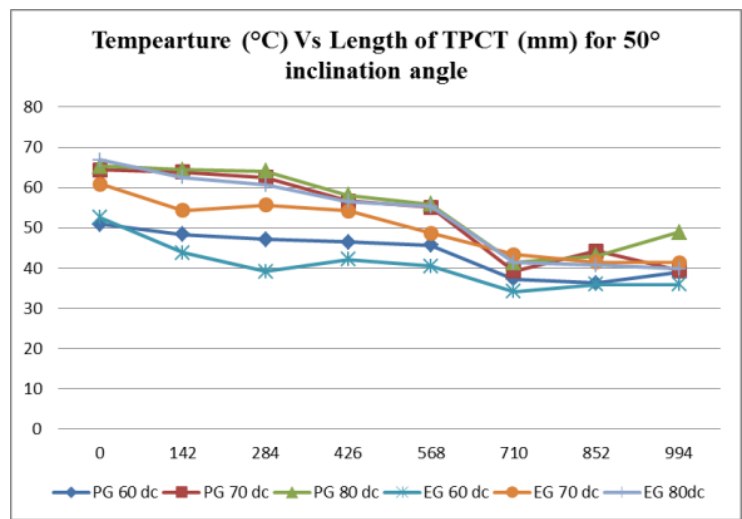

Figure 7: Plot of Temperature $\left({ }^{\circ} \mathrm{C}\right)$ Vs Length of TPCT $(\mathrm{mm})$ for $50^{\circ}$ inclination angle 


\section{Remark on temperature distribution:}

1. We provide heat input at evaporator section but this total heat cannot transfer to condenser section due to heat loss and in adiabatic section temperature distribution along length is almost same.

2. Distribution of temperature along length of TPCT is in decreasing manner.

3. EG TPCT shows better temperature distribution over PG TPCT.

Variation of efficiency for inclination angle and heat input

Efficiency is the parameter use to represent the performance of TPCT. From obtained reading we have calculated the efficiency of TPCT for different inclination angle, heat input and fill volume ratio.

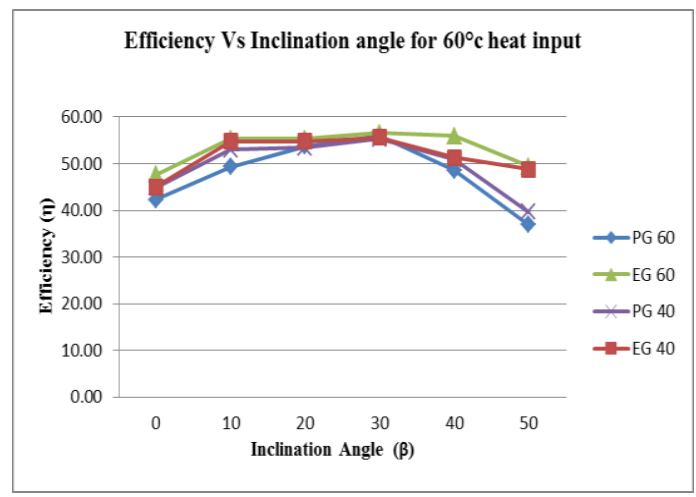

Figure 8: Plot of Efficiency Vs Inclination angle for $60^{\circ} \mathrm{c}$ heat input

\section{Remark on efficiency:}

With lower heat input, the EG pipe shows better efficiency compared to PG TPCT.EG TPCT with $60 \%$ fill volume shows better efficiency at 208 to 308 .

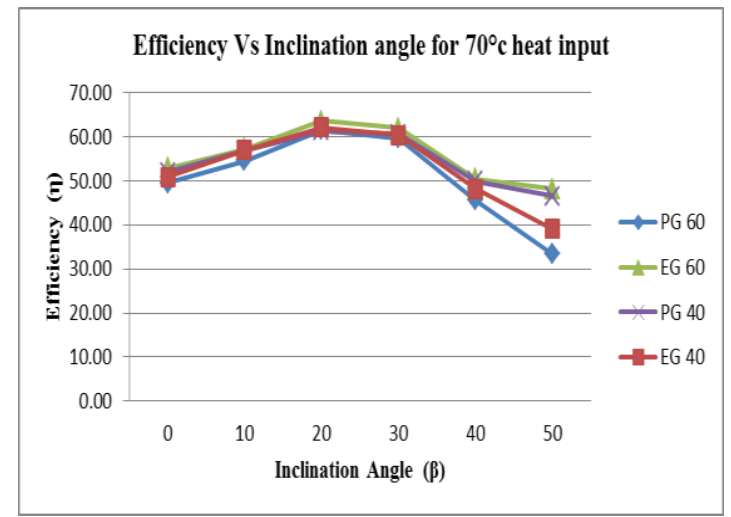

Figure 9: Plot of Efficiency Vs Inclination angle for $70^{\circ} \mathrm{c}$ heat input

\section{Remark on efficiency:}

With respect to increase in a heat input, the efficiency of TPCT is getting improved. The EG TPCT pipe works well with increasing inclination angle upto 30degree, beyond which efficiency decrease. The PG pipe works good with increasing inclination angle upto 30degree, beyond which efficiency decrease.

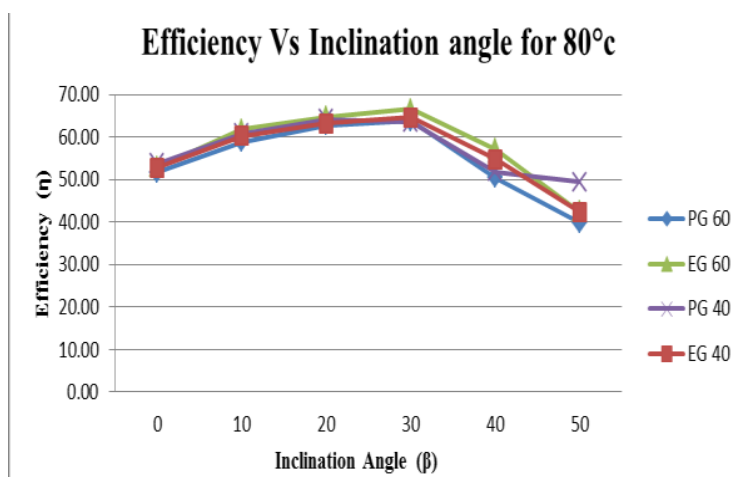

Figure 10: Plot of Efficiency Vs Inclination angle for $80^{\circ} \mathrm{c}$ heat input 
Remark on efficiency:

The maximum Efficiency of PG pipe is $64.20 \%$ found to be at a heat input of 80dc, at an inclination of 30degree. The maximum Efficiency of EG (60), pipe is $66.57 \%$ found to be at a heat input of $80 \mathrm{dc}$, at an inclination of 30 degree.

\subsection{Thermal resistance of TPCT with different heat input}

Thermal resistance is the thermodynamic property used to represent conductivity of heat from evaporator to condenser section. It is required to be minimum thermal resistance for better performance of TPCT.

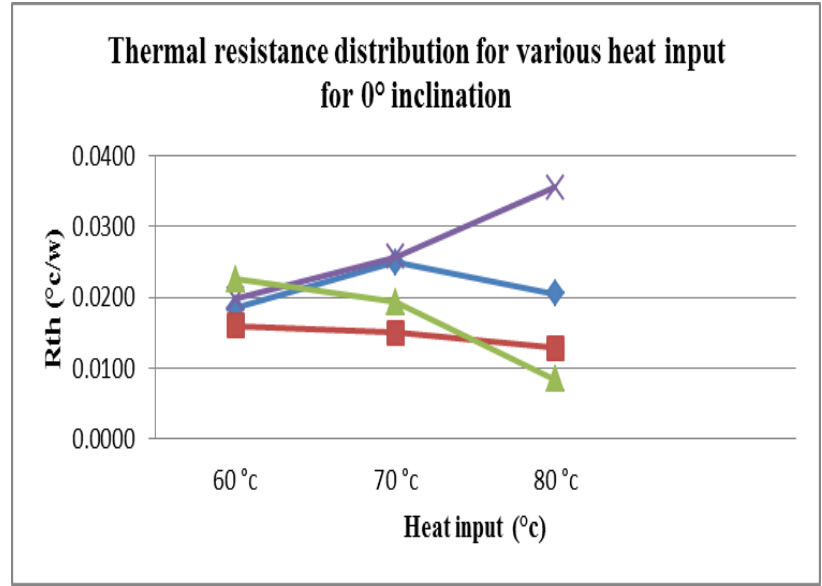

Figure 11: Plot of Thermal resistance Vs Heat input for $0^{\circ}$ inclination

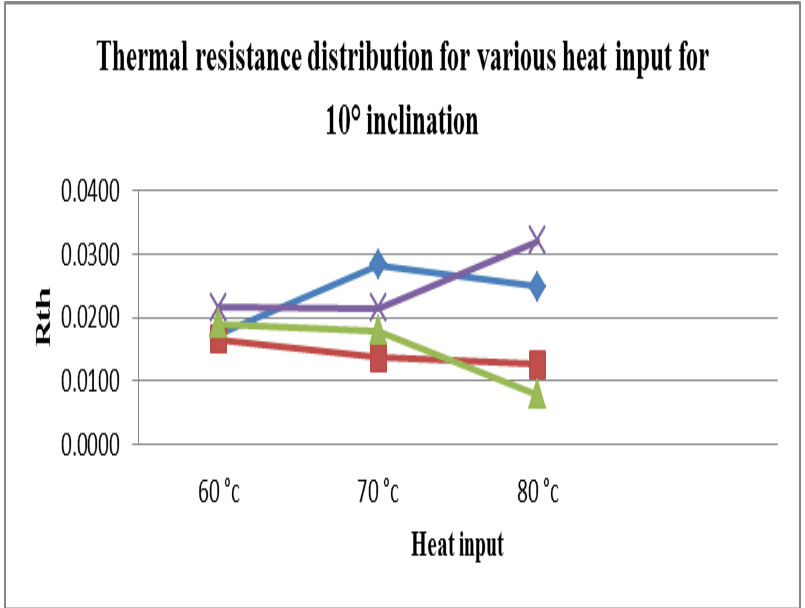

Figure 12: Plot of Thermal resistance Vs Heat input for $10^{\circ}$ inclination

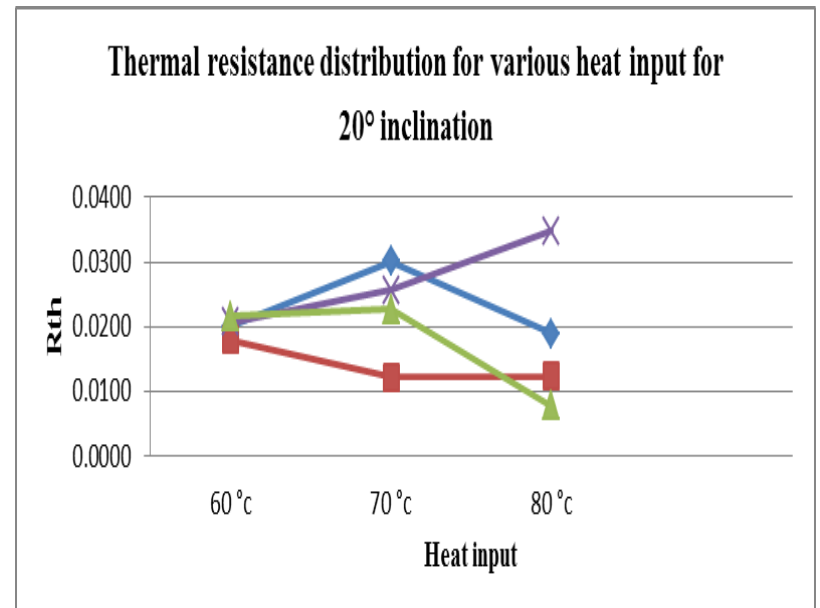

Figure 13: Plot of Thermal resistance Vs Heat input for $20^{\circ}$ inclination 


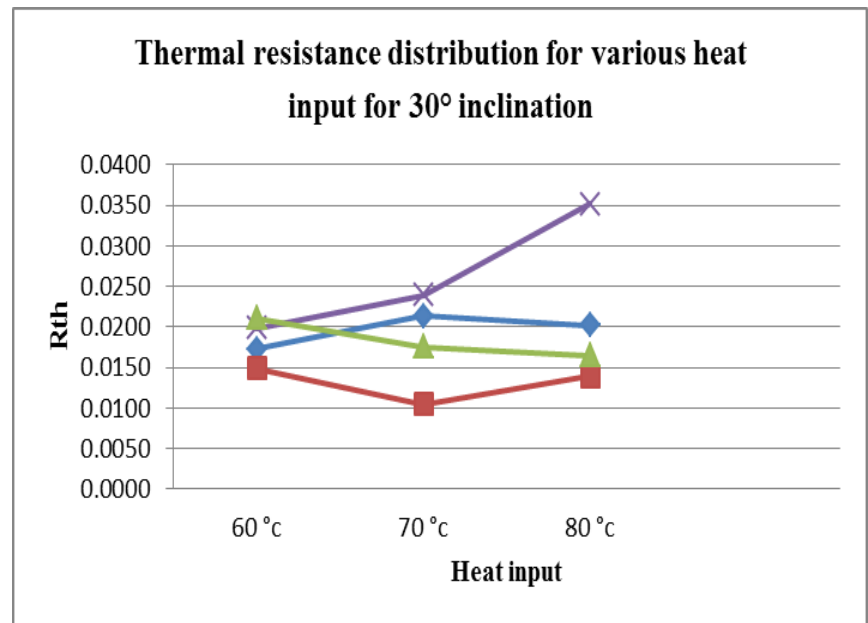

Figure 14: Plot of Thermal resistance Vs Heat input for $30^{\circ}$ inclination

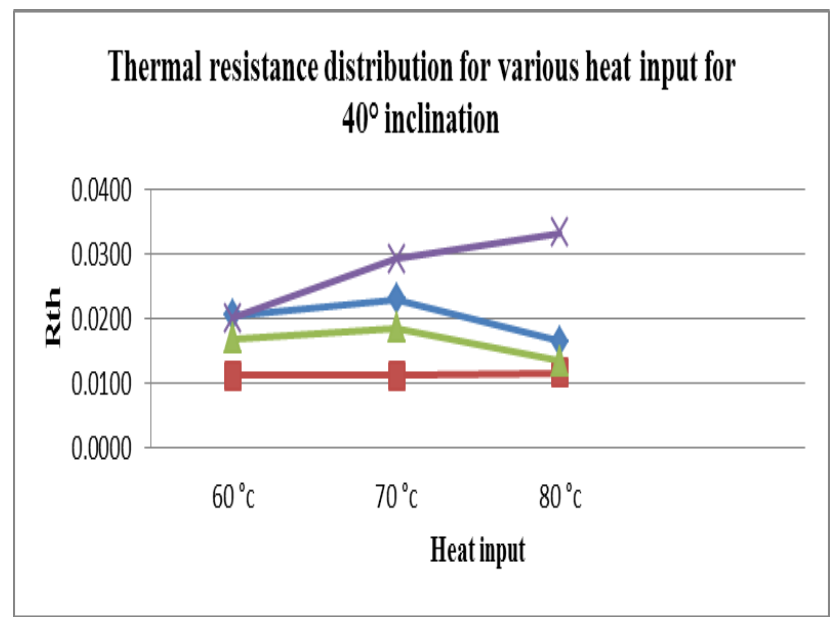

Figure 15: Plot of Thermal resistance Vs Heat input for $40^{\circ}$ inclination

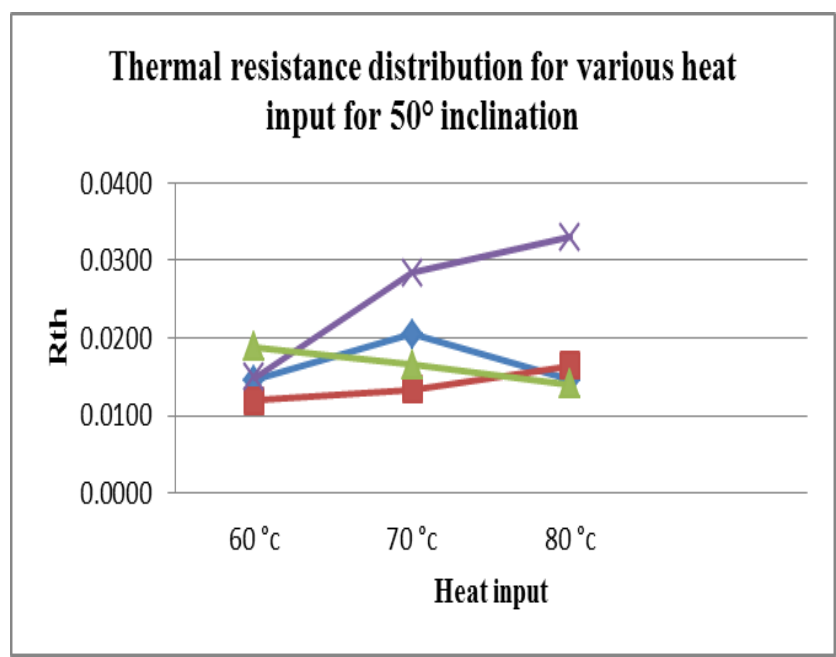

Figure 16: Plot of Thermal resistance Vs Heat input for $50^{\circ}$ inclination

\section{Remark on thermal resistance:}

1. Thermal Resistance of EG TPCT is less than PG TPCT.

2. As the heat input increases thermal resistance decreases for EG TPCT with $40 \%$ fill volume.

3. As the heat input increases thermal resistance increased for EG TPCT with $60 \%$ fill volume.

4. Maximum thermal resistances occur for PG TPCT with $40 \%$ fill volume.

5. Thermal resistance for PG, TPCT with $60 \%$ fill volume increases up to $708 \mathrm{c}$ and further decreases. 


\subsection{Thermal resistance of TPCT with different inclination angle}

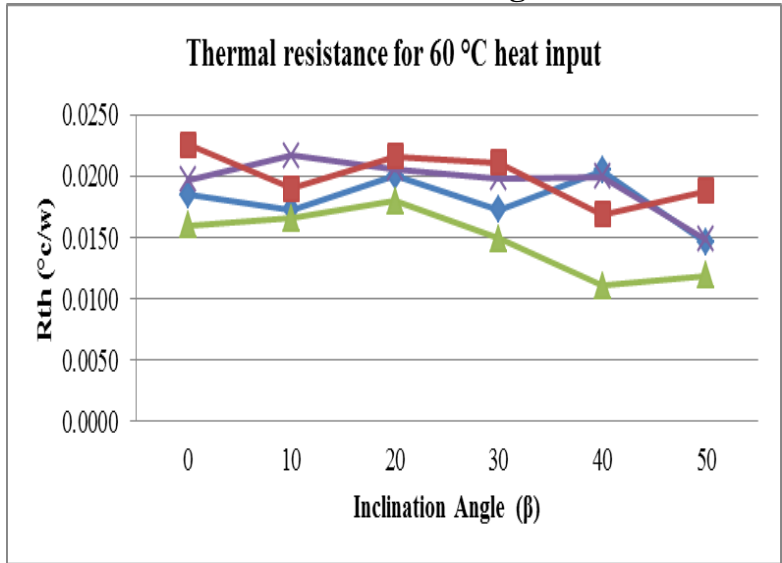

Figure 17: Plot of Thermal resistance Vs different inclination angle for $60{ }^{\circ} \mathrm{C}$ heat input

Remark on thermal resistance with respect to inclination angle:

TPCT shows higher thermal resistance at lower heat input. There is random variation in thermal resistance with respect to inclination angle. EG TPCT with $60 \%$ fill volume shows lower thermal resistance at $608 \mathrm{c}$ heat input.

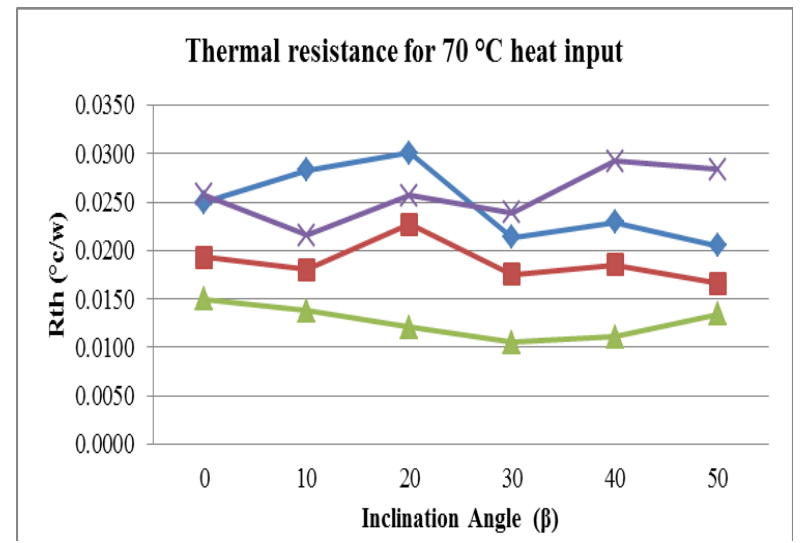

Figure 18: Plot of Thermal resistance Vs different inclination angle for $70{ }^{\circ} \mathrm{C}$ heat input

Remark on thermal resistance with respect to inclination angle:

As the heat input increases thermal resistance of PG TPCT increases and thermal resistance of EG TPCT decreases. PG TPCT with $60 \%$ fill volume shows the higher thermal resistance.

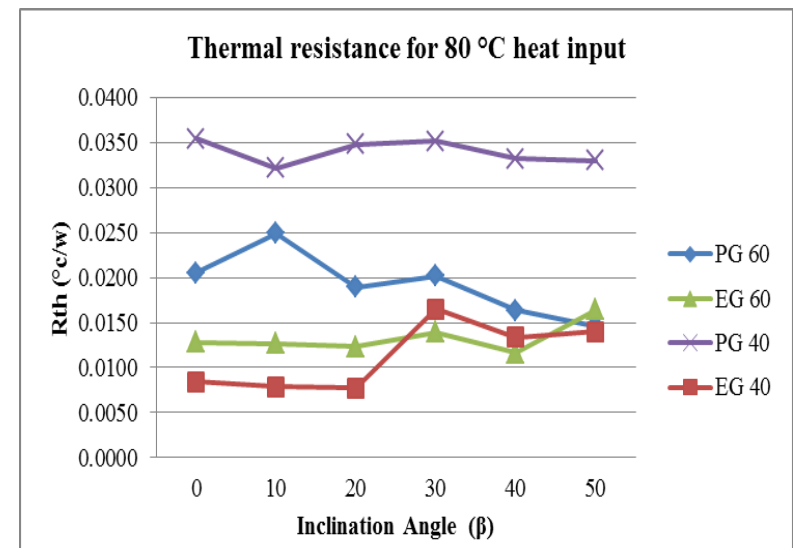

Figure 19: Plot of Thermal resistance Vs different inclination angle for $80^{\circ} \mathrm{C}$ heat input

Remark on thermal resistance with respect to inclination angle:

Plot shows lower variation in EG TPCT with $60 \%$ fill volume. As inclination angle increases the thermal resistance of EG TPCT is almost constant up to $20^{\circ}$ inclination angle and further random in nature. 


\section{Conclusion}

1. With respect to increase in a heat input, the efficiency of TPCT is getting improved.

2. For higher heat input EG TPCT found to be work better than PG TPCT.

3. With lower heat input, the EG pipe shows better efficiency compared to PG pipe.

4. EG pipe shows better efficiency compared to all other pipes at maximum inclination angle.

5. The PG pipe works well with increasing inclination angle upto 30 degree, beyond which efficiency decrease.

6. The EG TPCT pipe works well with increasing inclination angle upto 30degree, beyond which efficiency decrease.

7. EG TPCT shows less thermal resistance over PG TPCT.

8. For EG TPCT with $60 \%$ fill volume and PG TPCT with $40 \%$ fill volume shows decreasing thermal resistance as heat input increases.

9. EG TPCT with $40 \%$ fill volume and PG TPCT with $60 \%$ fill volume shows increasing thermal resistance as heat input increases.

10. There is random variation in thermal resistance with respect to inclination angle.

11. Heat transfer rate is found to be improved for EG TPCT at 808 cover all inclination angles.

\section{References}

[1] Reay D. A. and Kew P.A., "Heat pipes - Theory, Design and Applications", $5^{\text {th }}$ ed., Butterworth Heinemann, UK, 2006, pp.1 - 2.

[2] H. Li, A. Akbarzadeh and P. Johnson, "The thermal characteristics of a closed two-phase thermosyphon at low temperature difference", Heat Recovery Systems \& CHP, 1991, 11(6), pp. 533-540.

[3] Wei Guo, Darin W. Nutter, "An experimental study of axial conduction through a thermosyphon pipe wall", Applied Thermal Engineering, 2009, 29, pp. 3536-3541.

[4] A. Kate and R. Kulkarni, "Effect of Pipe Cross Section Geometries and Inclination Angle on Heat Transfer Characteristics of Wickless Heat Pipe", International Journal of Engineering Research and Technology, 2010, 3(3), pp. 699-710.

[5] M. Karthikeyan, S. Vaidyanathan, B. Sivaraman, "Thermal performance of a two phase closed thermosyphon using aqueous solution", International Journal of Engineering Science and Technology, 2010,2 (5), pp. 913-918.

[6] Yogesh S. Gandal, "Experimental Investigation of Two Phase Closed Thermosyphon Using Propylene Glycol As a working Fluid", August 2014, ISSN: 2278-0181, Volume 3.

[7] E. Hahne and U. Gross, "The influence of the inclination angle on the performance of a closed two phase thermosyphon", Heat recovery system, 1981, 1, pp. 267-274.

[8] C. Wang, D.Q. Xn and S.P. Li, "Investigation of heat transfer on the Dowtherm A gravity assisted heat pipe", Heat and Mass transfer, 1993, 29, pp. 1-8

[9] H. Nguyen-chi and M. Groll, "Entrainment or flooding limit in a closed two phase thermosyphon", Heat Recovery System, 1981, 1, pp. 275-286.

[10] Stephane lips and Josua P. Meyer, "Experimental study of convective condensation in an inclined smooth tube." Part 1: Inclination effect on flow pattern and heat transfer coefficient, 55(2012), pp. 395-404 